\title{
Fenologia reprodutiva de Dipteryx odorata (Aubl.) Willd (Fabaceae) em duas áreas de floresta na Amazônia Central
}

\author{
Antonio Moçambite PINTO ${ }^{1,2}$, L. P. C. MORELLATO ${ }^{1}$, Antenor Pereira BARBOSA ${ }^{2}$
}

\section{RESUMO}

Estudos fenológicos de longa duração em florestas tropicais são raros. Foi realizado o acompanhamento fenológico de Dipteryx odorata, no período de 1974 à 2000, em duas áreas de floresta amazônica: a Reserva Florestal Ducke (RFD) e Estação Experimental de Silvicultura Tropical (EEST). O objetivo foi observar os padrōes fenológicos nas duas áreas, verificar a regularidade da floração e frutificação num período de 27 anos e a influência dos fatores climáticos nestes eventos. Foram marcados cinco indivíduos na RFD e cinco na EEST e observados quanto à produção de flores, frutos imaturos e maduros. A floração e a produção de frutos imaturos apresentaram padrão irregular nas duas áreas observadas, variando quanto a época de ocorrência e a duração entre anos e estações, mas apresentaram freqüência de ocorrência similar nos 27 anos observados. Para a fenofase frutos maduros este padrão foi diferente, com intervalos de até três anos sem ocorrência de frutos maduros, na RFD e de sete anos na EEST. Conclui-se que a freqüência de ocorrência das fenofases de floração e frutos imaturos foi anual e a de frutos maduros supra-anual, todas com padrão irregular e duração de intermediária a prolongada. Ocorreu variação de um a três anos entre episódios de floração e frutos imaturos e de um a sete anos entre episódios de frutos maduros, não ficando evidente, nesta análise, a influência dos fatores climáticos nos padrões observados. Sugere-se o uso racional dos produtos derivados de Dipteryx odorata, o cumaru, especialmente quanto à exploração de seus frutos e o desenvolvimento de mais estudos de longa duração, fundamentais para entender os padróes fenológicos reprodutivos e de oferta de recursos em florestas tropicais.

PALAVRAS-CHAVE: Fenologia reprodutiva, Dipteryx odorata, floração, frutificação, Amazônia Central.

\section{Reproductive phenology of Dipteryx odorata (Aubl.) Willd (Fabaceae) in two forest areas in the Central Amazon.}

\begin{abstract}
Long term phenological studies in tropical forests are scarce. A phenological study of Dipteryx odorata was carried out from 1974 to 2000 in two areas of Amazon Forest: Reserva Florestal Ducke (RFD) and Estação Experimental de Silvicultura Tropical (EEST). The objective was to compare the phenological patterns between the two areas, to verify the regularity of flowering and fruiting over a period of 27 years, and to verify the influence of climatic factors in these events. Five trees were marked in the RFD and five in the EEST; and were observed monthly for the presence of flowers, unripe and ripe fruits. The flowering and unripe fruiting presented an irregular pattern in both areas, and also varied with regard to duration and period of occurrence between years and seasons. Nevertheless, they presented similar frequency of occurrence during the 27 years of observation. On the other hand, the production of ripe fruits presented a different pattern, with three year intervals without ripe fruits in the RFD, and seven year intervals in the EEST. We concluded that the frequency of flowering and unripe fruiting was annual, and the frequency of occurrence of ripe fruiting was supra-annual, with an irregular pattern, and a duration from intermediate to extended. We also observed the occurrence of one to three year intervals between flowering and unripe fruiting episodes, and one to seven year intervals between episodes with ripe fruiting. The influence of climatic factors in the patterns observed was not clear. We suggest the rational use of natural products extracted from Dipteryx odorata, the "cumaru", especially the fruits, and the development of more long term studies, fundamental for understanding the reproductive phenological patterns as well as the resource offering patterns in tropical forests.
\end{abstract}

KEY WORDS: reproductive phenology, Dipteryx odorata, flowering, fruiting, Central Amazon.

\footnotetext{
1 Universidade Estadual Paulista, UNESP, Instituto de Biociências, Departamento de Botânica, Grupo de Fenologia e Dispersão de sementes, Caixa Postal 199, $13506-900$ - Rio Claro, SP.

2 Instituto Nacional de Pesquisas da Amazônia - INPA, CPST, Caixa Postal 478, 69011-970 - Manaus, AM. ampinto@inpa.gov.br
} 


\section{INTRODUÇÃO}

A fenologia é de fundamental importância para a silvicultura, manejo florestal e ecologia, pois estuda os fenômenos naturais repetitivos, como os ritmos de floração, frutificação e mudança foliar e sua relação especialmente com o clima (Lieth 1974). Muitos processos fenológicos, como a queda de folhas e a floração, estão claramente relacionados ao clima, e fatores climáticos e ecológicos tem sido associados à fenologia de espécies florestais tropicais (Rathcke \& Lacey 1985, Van Schaik et al.1993, Wright \& Van Schaik 1994). Muitos eventos fenológicos, especialmente os reprodutivos, ocorrem com freqüência supra-anual e sua detecção depende de estudos de longa duração (Newstron et al. 1994a e b). Entretanto, são raros os estudos fenológicos de longa duração em florestas tropicais com observação direta de plantas, não ultrapassando em geral 10 anos de observações (Chapman et al. 2005, Newstron et al. 1994 a, b). Na América do sul estes estudos são também escassos (Morellato 2003), com exceção dos estudos pioneiros de Araujo (1970) e Alencar et al.(1979) em floresta de terra firme na Amazônia Central.

Este trabalho é parte de um estudo fenológico de longa duração iniciado em 1965 na Reserva Florestal Ducke (RFD) (Araújo, 1970; Alencar et al., 1979) e em 1974 na Estação Experimental de Silvicultura Tropical (EEST), ambos em floresta de terra firme na região de Manaus, Amazonas. Trata-se de uma investigação dos eventos fenológicos de cerca de 200 espécies florestais tropicais com a finalidade de oferecer subsídios aos planos de manejo e reflorestamento de áreas degradadas na floresta Amazônica.

Várias publicaçóes sobre a fenologia de árvores na Amazônia Central foram geradas com os dados da Reserva Florestal Ducke. Estas publicações enfocam comunidades (Araújo, 1970; Alencar et al. 1979), e populações (Magalhães \& Alencar 1979, Alencar 1988, Umaña \& Alencar 1993, Ruiz \& Alencar 2004, Pinto et al. 2005). Estudos sobre a fenologia de espécies de Lecythidaceae (Lima Júnior 1992), de Sapotaceae (Alencar 1994) e de Chrysobalanaceae (Ruiz \&Alencar 1999) também foram produzidos. Todos estes trabalhos, embora incluam vários anos de observações fenológicas, raramente analisam as séries temporais (Alencar 1994) e sim a média fenológica para aquele intervalo de anos.

Dipteryx odorata (Aubl.) Willd, (Fabaceae), o cumaru, é uma espécie arbórea de grande porte, atingindo até $30 \mathrm{~m}$ de altura na floresta primária, porém de porte mais baixo quando cultivada ou em florestas secundárias (Loureiro et al., 1979; Clay et al., 1999; Revilla, 2000). Esta espécie é tida como importante para reflorestamentos, frutificando precocemente aos quatro anos de idade. Sua madeira é utilizada para a produção de implementos agrícolas, na construção naval, na confecção de cabos de ferramentas, de moirōes, de dormentes, de carroças, de estacas, de esteios, de tacos para assoalhos, de vigamentos, de artigos laminados de marcenaria, bem como de buchas de eixo de hélices de embarcaçóes (Silva et al., 1977; Loureiro et al., 1979). As amêndoas dos frutos são aromáticas, de onde se extrai óleo essencial usado em perfumaria (cumarina), de grande importância na economia regional e de importância industrial na Venezuela (Loureiro et al., 1979). A tintura da casca do fruto é antiespasmódica e tônica e eficaz moderador dos movimentos cardíacos e da respiração (Loureiro et al. 1979, Clay et al. 1999). Dessa forma, o estudo fenológico desta espécie possibilita a determinação da regularidade e previsibilidade na oferta deste recurso natural, com a finalidade de possibilitar o uso mais racional dos produtos florestais da Amazônia.

Este trabalho tem como objetivos: 1. determinar os padrōes de floração e frutificação de Dipteryx odorata ao longo de 27 anos de observaçôes; 2. comparar os eventos fenológicos em duas áreas distintas de floresta de terra firme, a Reserva Florestal Ducke e a Estação Experimental de Silvicultura Tropical, de forma a averiguar se esta espécie apresenta comportamento fenológico similar em resposta a fatores climáticos semelhantes ao longo do tempo.

\section{MATERIAL E MÉTODOS}

\section{ÁREA DE ESTUDO}

O estudo foi desenvolvido em duas áreas de floresta tropical úmida de terra firme: a Reserva Florestal Ducke (RFD), situada à $26 \mathrm{~km}$ ao norte de Manaus, na Estrada Manaus-Itacoatiara (AM-010) com 10.072 ha., (0300'00" a $03^{\circ} 08^{\prime} 00^{\prime \prime}$ S e $59^{\circ} 52^{\prime} 40^{\prime \prime}$ a $59^{\circ} 52^{\prime} 00^{\prime \prime}$ W) (Ribeiro, 1976) e a Estação Experimental de Silvicultura Tropical (EEST) com 180.000 ha. (2॰37' a $2^{\circ} 38^{\prime}$ S e $60^{\circ} 09^{\prime}$ a $60^{\circ} 11^{\prime}$ W), distando cerca de $45 \mathrm{~km}$ ao norte de Manaus na Rodovia ManausCaracarai BR-174 (RADAM BRASIL, 1978).

O clima da região é do tipo Afi, de acordo com a classificação de Köppen: $A$ - Clima tropical praticamente sem inverno, sendo a temperatura média para o mês mais frio nunca inferior a $18^{\circ} \mathrm{C} ; f$ - chuvas durante todo o ano; $i-$ indica isotermia, ou seja, as oscilações anuais de temperatura média não chegam a $5^{\circ} \mathrm{C}$; não há verão nem inverno (Ribeiro, 1976). Os dados climatológicos utilizados para os dois locais em estudo (RFD e EEST) foram coletados na Estação Climatológica da RFD e fornecidos pela Coordenação de Pesquisas em Ciência do Ambiente do Instituto Nacional de Pesquisas da Amazônia (INPA), sendo que a distância entre a RFD e EEST é de aproximadamente $30 \mathrm{~km}$ em linha reta. No diagrama climático obtido a partir de dados de 27 anos (entre 1974 a 2000) observa-se a existência de um período super úmido, que se estende de novembro a maio, com chuvas freqüentes alcançando médias mensais acima de 200 $\mathrm{mm}$ e as menores temperaturas médias mensais, denominada 
estação chuvosa. Um período menos úmido ocorre durante os meses de junho a outubro, com chuvas menos constantes, mas sem déficit hídrico, com precipitação média de 133,5 $\mathrm{mm}$ mensais e maiores temperaturas médias mensais (Fig. 1), sendo considerado como a estação seca. $\mathrm{O}$ mês mais seco foi agosto e abril o mês com a maior média de precipitação $(304,34 \mathrm{~mm})$. A temperatura média mensal variou pouco, entre $25,5^{\circ} \mathrm{C}$ e $26,7^{\circ} \mathrm{C}$. As temperaturas médias máximas mais elevadas $\left(30,8^{\circ} \mathrm{C}\right.$ a $\left.33,4^{\circ} \mathrm{C}\right)$ ocorrem no final da estação seca e os menores na estação chuvosa (Fig. 1).

A vegetação predominante da região foi classificada por Ducke \& Black (1954) como floresta tropical úmida e está incluída na "Floresta ombrófila densa" da Amazônia (Veloso et al., 1991). Alencar (1986) nomeia a floresta da Reserva Florestal Ducke como tropical úmida de terra firme, caracterizada por grande diversidade de espécies arbóreas, arbustivas e herbáceas. As florestas estudadas apresentam aspecto sempre verde, pois as árvores nunca perdem toda a folhagem ao mesmo tempo, e grande número de espécies arbóreas, geralmente distribuídas em três estratos bem distintos. O estrato superior ou dominante é formado por árvores de grande porte, com DAP (diâmetro à altura do peito) superior a 1,00 m, e altura

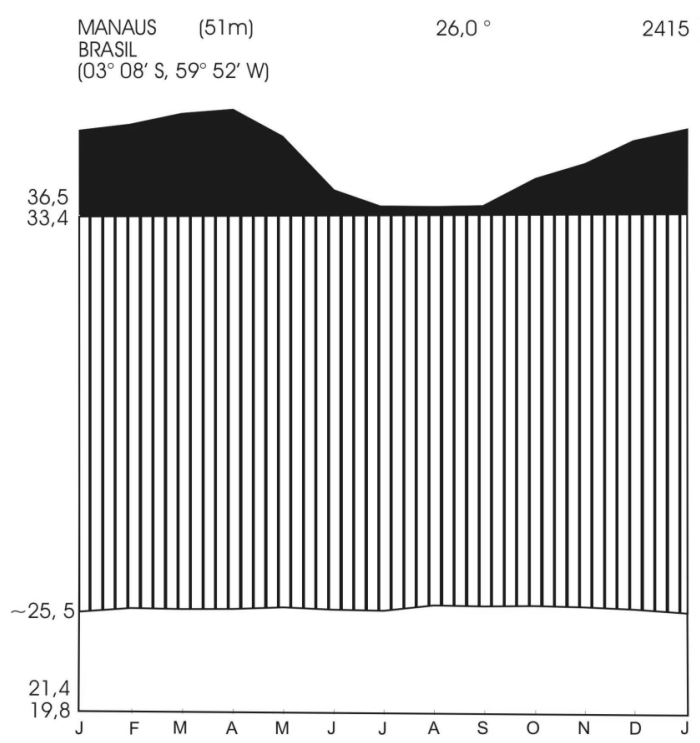

Figura 1 - Diagrama climático para a região de Manaus, para o período de 1974 a 2000, segundo Walter \& Lieth (1960-67). A curva inferior mostra a temperatura média mensal (intervalos de $10^{\circ} \mathrm{C}$ no eixo y); na curva superior, a precipitação média mensal total (intervalos de $20 \mathrm{~mm}$ no eixo y), exceto para zona preta , que representa períodos super úmidos, com precipitação superior a $100 \mathrm{~mm}$ por mês - quando a escala é reduzida a 1/10. Zona com traços: período úmido. Acima, no gráfico, são mostradas a altitude, temperatura média anual e precipitação $(\mathrm{mm})$. Temperaturas à esquerda, lidas a partir do topo, são: máxima absoluta, média das máximas do mês mais quente, variação média diária de temperatura, média das mínimas para o mês mais frio e mínima absoluta. da copa, às vezes, chegando a $45 \mathrm{~m}$ ou mais como Cedrelinga catenaeformis Ducke (cedrorana) e Dinizia excelsa Ducke (angelim pedra); o estrato intermediário é composto por árvores de porte menor, cujos DAP pode ir além de $1,00 \mathrm{~m}$, porém a altura da copa geralmente está abaixo de $45 \mathrm{~m}$, como Enterolobium schomburgkii Bth (sucupira amarela) e Aniba duckei Kostermans (pau rosa), e palmeiras como o "açai" (Euterpe oleracea Mart.) e o "buritirana" (Mauritia aculeata H.B.K.); o estrato inferior é constituído de espécies que se desenvolvem em condiçōes de forte sombra, como as palmeiras Geonoma deversa (Poit) Kunth. (ubim) e Manicaria saccifera Gaert. (buçu) e outras plantas arbustivas e herbáceas.

A escolha das árvores obedeceu a uma série de critérios silviculturais e ecológicos definidos por Araújo (1970), como ter fuste e copa perfeitos, não serem jovens, possuírem grande porte, e estão amplamente distribuídas pelas áreas de estudo. Foram amostrados cinco indivíduos de Dipteryx odorata na RFD e cinco na EEST, observados mensalmente com auxílio de binóculo para o registro da presença e ausência das fenofases, conforme descrito em Alencar et al. (1979). Neste estudo, foram analisadas as fenofases floração (período de antese ou flores abertas) e frutificação, dividida em frutos imaturos (frutos novos em formação) e frutos maduros (frutos maduros presentes) para o período de janeiro de 1974 a dezembro de 2000.

Os padrões fenológicos foram descritos segundo Newstrom et al. (1994 a e b) de acordo com sua freqüência - número de ciclos com e sem fenofases por ano; regularidade - dada pela variabilidade de época de ocorrência e duração das fases, sendo duração o tempo em meses que um indivíduo permanece em uma dada fase.

Foi calculada a relação entre os dados fenológicos com as variáveis climáticas (precipitação e temperaturas - máxima, média e mínima), por meio de análise não paramétrica de correlação linear de Spearman (Zar, 1996) considerando os valores médios mensais das variáveis climáticas.

\section{RESULTADOS}

A floração de Dipteryx odorata na RFD apresentou frequiência anual, embora não tenha mostrado regularidade quanto a época de ocorrência, que em geral recaiu entre as estações seca e chuvosa (Fig. 2B) e apresentou correlação positiva significativa fraca (entre 0 e 0,5 ) com a temperatura mínima $\left(r_{s}=0,22 ; p<0,01\right)$. Foi registrado pico de ocorrência nos anos de 1983 (jan, fev), 1984 (jul, ago, set, out, nov, dez) e 1993 (nov,dez). O maior intervalo ocorreu entre 1980 a 1981, num período de 2 anos, em 1989 e em 1991 (Fig. 2B).

A floração de Dipteryx odorata na EEST apresentou freqüência anual, ocorrendo em geral na estação seca e transição seca para chuvosa (Fig. 2A) e apresentou correlação 


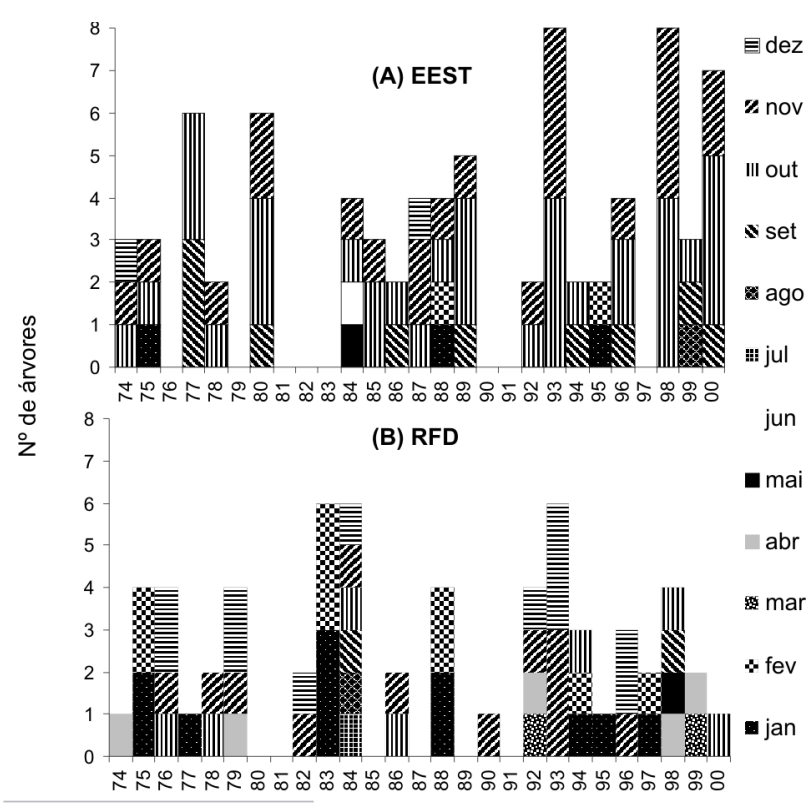

Figura 2 - Padrão de floração (antese) de Dipteryx odorata em número de árvores florescendo por mês, em cada ano de observação, em (A) Estação Experimental de Silvicultura Tropical $(n=5)$ e em (B) Reserva Florestal Ducke $(n=5)$, do Instituto Nacional de Pesquisas da Amazônia - INPA, Manaus, AM.

positiva significativa fraca com a temperatura máxima $\left(\mathrm{r}_{\mathrm{s}}=\right.$ $0,30 ; \mathrm{p}<0,01)$ e temperatura média $\left(\mathrm{r}_{\mathrm{s}}=0,15 ; \mathrm{p}<0,01\right)$. A época de maior produção de flores no período de estudo ocorreu nos anos de 1993 e 1998 (out, nov). Os maiores intervalos foram observados entre 1981 a 1983 e entre 1990 a 1991 num período de 3 e 2 anos, respectivamente e em 1976 (Fig. 2A).

A produção de frutos imaturos na RFD, mostrou freqüência com tendência a anual, em geral na estação chuvosa (Fig. 3B), e apresentou correlação positiva significativa fraca com a precipitação $\left(r_{s}=0,27 ; p<0,01\right)$ e temperatura mínima $\left(r_{s}=0,13 ; p<0,05\right)$ e correlação negativa significativa fraca com a temperatura máxima $\left(\mathrm{r}_{\mathrm{s}}=-0,12 ; \mathrm{p}<0,05\right)$. Pico de ocorrência foi nos anos de 1975 (mar, abr, mai, jun) e 1983 (mar, abr, mai). O maior intervalo entre frutificação foi de três anos (1980 a 1982) (Fig. 3B).

$\mathrm{Na}$ EEST, a produção de frutos imaturos também apresentou freqüência anual, recaindo em geral na estação chuvosa, principalmente em novembro e dezembro (Fig. $3 \mathrm{~A})$, e apresentou fraca correlação positiva significativa com a precipitação $\left(r_{s}=0,27 ; p<0,01\right)$ e negativa significativa com a temperatura máxima $\left(r_{s}=-0,20 ; p<0,01\right)$. O maior pico de ocorrência ocorreu de outubro de 1989 à junho de 1990, e o maior intervalo foi observado entre 1982 e 1983, num período de 2 anos (Fig. 3A).

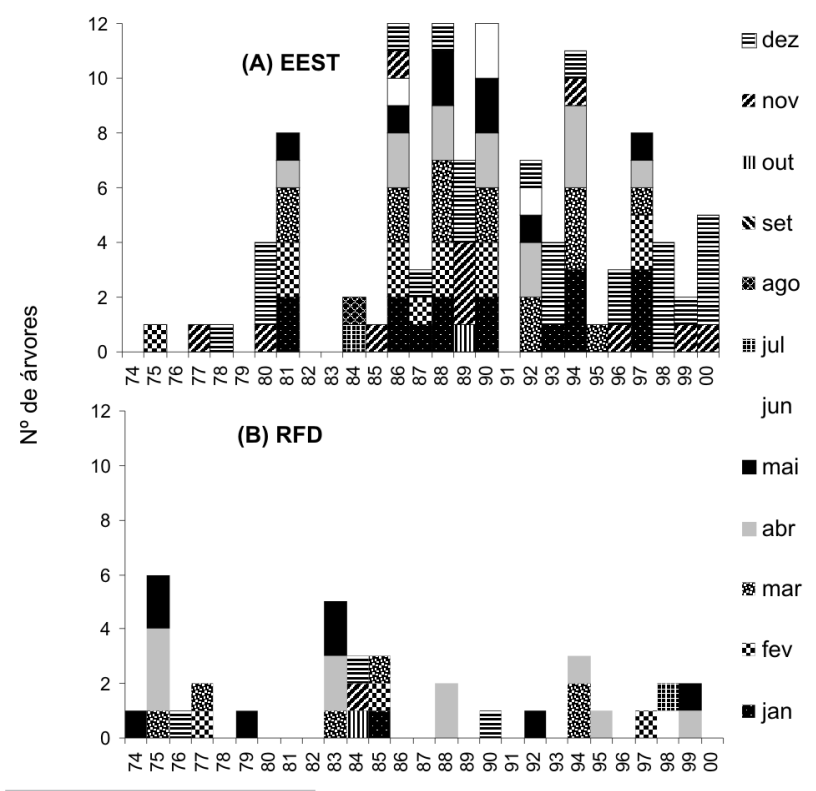

Figura 3 - Padrão de frutificação (frutos imaturos) de Dipteryx odorata em número de árvores frutificando por mês, em cada ano de observação, em (A) Estação Experimental de Silvicultura Tropical $(n=5)$ e em (B) Reserva Florestal Ducke $(n=5)$, do Instituto Nacional de Pesquisas da Amazônia INPA, Manaus, AM.

A fenofase frutos maduros mostrou tendência a freqüência supra-anual na RFD, ocorrendo em geral na estação seca e na transição seca-chuvosa (Fig. 4B) e apresentou correlação negativa significativa fraca com a temperatura máxima $\left(\mathrm{r}_{\mathrm{s}}=-\right.$ 0,12; $\mathrm{p}<0,05)$ com um pico de ocorrência no ano de 1994 (abr, mai, jun, jul). Apresentou maiores intervalos (três anos) entre 1980 a 1982 e entre 1989 a 1991; de dois anos em 8687 e $95-96$ e de um ano em 78 (Fig. 4B).

$\mathrm{Na}$ EEST a produção de frutos maduros ocorreu na estação seca e com padrão supra-anual (Fig. 4A), sem correlação com fatores climáticos. O maior intervalo entre observaçōes ocorreu de 1974 a 1980, num período de 7 anos (Fig. 4A). Nesta área, a ocorrência de frutos maduros foi considerada rara.

$\mathrm{Na} R F D$, as fenofases com duração de quatro meses foram as mais freqüentes, seguidas de um ou dois meses de duração para a floração e frutos imaturos e duração entre três e um meses para frutos maduros. Para a frutificação e floração o período de duração total não excedeu seis meses (Tabela 1). $\mathrm{Na}$ EEST a duração da floração mais freqüentemente foi de dois meses; a duração da fenofase frutos imaturos foi de um a dois meses e de um mês para fenofase frutos maduros (Tabela 1). Entretanto, alguns indivíduos apresentaram frutos imaturos por até nove meses. 


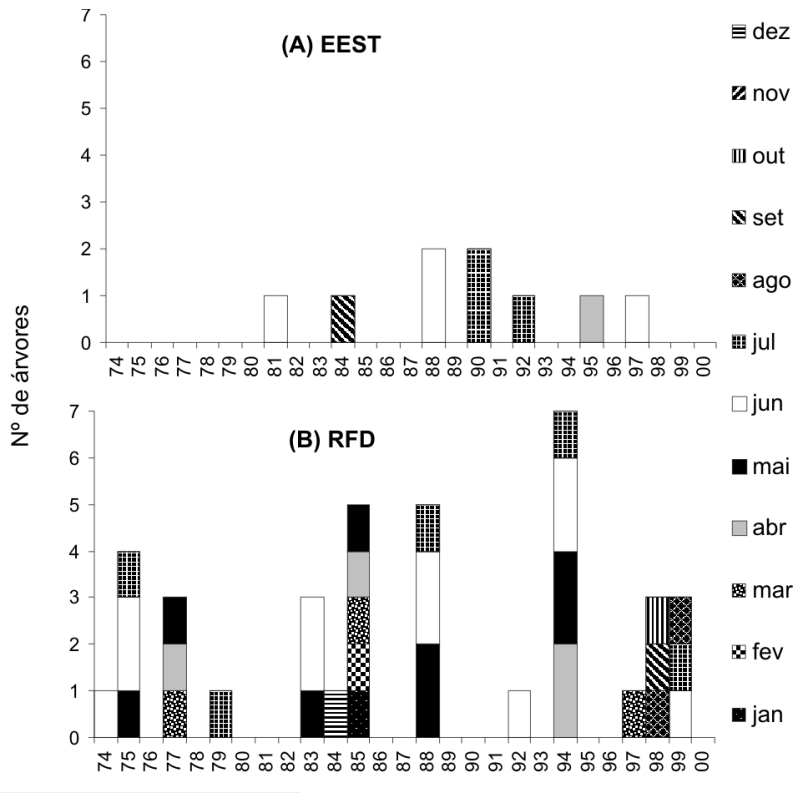

Figura 4 - Padrão de frutificação (frutos maduros) de Dipteryx odorata em número de árvores frutificando por mês, em cada ano de observação, em (A) Estação Experimental de SilviculturaTropical $(n=5)$ eem(B)Reserva Florestal Ducke( $n=5)$, do Instituto Nacional de Pesquisas da Amazônia - INPA, Manaus, AM.

Tabela 1 - Porcentagem de indivíduos de Dipteryx odorata, por categoria de duração de cada fenofase, na Estação Experimental de Silvicultura Tropical (EEST) e Reserva Florestal Ducke (RFD), Manaus, AM. Período: 1974 a 2000.

\begin{tabular}{lllllll}
\hline \multirow{2}{*}{$\begin{array}{l}\text { Duraçãos } \\
\text { (meses) }\end{array}$} & EEST & \multicolumn{5}{c}{ RFD } \\
\hline 1 & - & 31,8 & 100 & 27,8 & 46,7 & 33,3 \\
\hline 1 & 57,9 & 31,8 & - & 27,8 & 33,3 & 8,3 \\
2 & $\begin{array}{l}\text { frutos } \\
\text { imaturos }\end{array}$ & $\begin{array}{l}\text { frutos } \\
\text { maduros }\end{array}$ & $\begin{array}{l}\text { floração } \\
\text { frutos } \\
\text { imaturos }\end{array}$ & $\begin{array}{l}\text { frutos } \\
\text { maduros }\end{array}$ \\
3 & 26,3 & - & - & 5,5 & 6,7 & 41,7 \\
4 & 10,5 & 9,1 & - & 33,3 & 6,7 & 8,3 \\
5 & 5,3 & 4,5 & - & - & - & - \\
6 & - & 9,1 & - & 5,6 & 6,7 & 8,3 \\
7 & - & 9,1 & - & - & - & - \\
8 & - & - & - & - & - & - \\
9 & - & 4,5 & - & - & - & - \\
Total & 100 & 100 & 100 & 100 & 100 & 100 \\
\hline
\end{tabular}

\section{DISCUSSÃO}

Os padrōes fenológicos aqui descritos foram baseados em uma amostra pequena de cinco indivíduos em cada área e as fracas correlações observadas com o clima devem ser vistas com cautela. Entretanto, o longo período de observações dá consistência e confiabilidade aos dados apresentados, compensando o viés imposto pelo pequeno tamanho da amostra (Morellato et al. dados não publicados).
A floração de $D$. odorata na RFD foi um evento anual e ocorreu principalmente na estação úmida, de outubro a fevereiro, com fraca correlação positiva com as menores temperaturas que ocorrem nesta estação. $\mathrm{Na}$ EEST a floração também foi anual, mas ocorreu de forma mais concentrada no final da estação seca e início da estação chuvosa, em setembro, outubro e novembro, com fraca correlação positiva com a temperatura máxima, diferindo da RFD em seu padrão e época de ocorrência. Resultados similares foram observados por Magalhães e Alencar (1979) para Aniba duckei, onde o padrão de floração difere entre comunidades florísticas e entre indivíduos da mesma espécie. $\mathrm{O}$ mesmo foi verificado por Araújo (1970), quanto à floração de Caryocar villosum, que ocorreu no início da estação seca (julho e agosto) na RFD, embora tenha florescido no final da estação seca (setembro e outubro) na Estação Experimental de Curuá-Una, no Estado do Pará (Pereira \& Pedroso, 1982). Por outro lado, Prance (1975) observou que Couepia edulis, nos municípios de Coari e Tefé, no Estado do Amazonas, apresentou floração entre os meses de fevereiro e março (estação chuvosa), não havendo diferença no padrão fenológico entre os dois locais de estudo com relação a estação climática. É difícil explicar porque indivíduos da mesma espécie, no mesmo tipo de vegetação, e em locais próximos entre si, apresentam divergência nos padrôes fenológicos, respondendo de forma diferente aos estímulos ambientais. Talvez variaçôes no microambiente oferecido em cada área, que pode ser bastante heterogêneo em florestas tropicais (Morellato et al. 2000) afetem a fenologia de Dypterix odorata e outras espécies arbóreas acima citadas.

De um modo geral a produção de frutos imaturos nas duas áreas de estudo (RFD e EEST) foi anual, iniciando na transição da estação seca para a chuvosa, estendendo-se até o período de maior precipitação. As correlaçōes positivas com a precipitação mostram uma tendência de produzir frutos na época de chuvas. Este padrão coincide com o verificado por Alencar et al. (1979) para a maioria das espécies estudadas na RFD e para as espécies observadas na região próxima a Belém (Pará) por Cavalcante (1988). Alencar (1994), estudando a fenologia de cinco espécies arbóreas tropicais de Sapotaceae, também verificou correlação positiva entre frutos maduros e umidade relativa e precipitação, mostrando que esta fenofase está ligada à estação chuvosa.

No entanto, a produção de frutos maduros de $D$. odorata apresentou padrão supra-anual, com intervalos variáveis, nos dois locais estudados, sem correlaçôes evidentes com fatores ambientais. Pedroni et al. (2002), estudando Copaifera langsdorffi, não encontraram correlação significativa entre a frutificação e a precipitação e temperatura, concordando com os padrōes encontrados para frutos maduros em Dipteryx odorata. Esta irregularidade na produção de frutos maduros sugere a ocorrência de predação dos frutos, especialmente na 
EEST, durante a maturação, como sugerido por Magalhães \& Alencar (1979).

Neste estudo, a duração da floração e da fenofase frutos imaturos na EEST mais frequente foi de dois meses e de um mês para frutos maduros. Na RFD, a maior freqüência de duração foi de quatro meses para floração e de três meses para frutos maduros. De modo similar num estudo ao longo de 12 anos envolvendo 27 espécies da RFD a duração da floração variou de um a sete meses, sendo a duração de três meses a mais freqüente (Alencar et al. 1979). Para a frutificação, a duração variou de um a nove meses, sendo a duração de cinco meses a mais freqüente (Alencar et al. 1979), superior ao observado para $D$. odorata na RFD. Lima Júnior (1992), estudando cinco espécies de Lecythidaceae na Reserva Florestal Ducke, observou duração média da frutificação de três a seis meses. Almeida \& Alves (2000), estudando a fenologia de duas espécies de Psychotria verificaram que a frutificação foi o evento fenológico de maior duração, tendo sido de 12 meses para frutos imaturos e de três meses para frutos maduros.

Portanto, Dipteryx odorata apresenta frutificação com duração mais curta do que o usualmente observado na Amazônia e em florestas tropicais em geral. O curto período de frutificação de plantas tropicais teria como explicação alternativa o fato das angiospermas terem que defender seus frutos contra o dano causado por herbívoros (Krebs, 1994). As plantas reduziriam o tempo de exposição dos frutos maduros, permanecendo com frutos verdes por muitos meses, amadurecendo aos poucos ao longo do período de frutificação (Howe \& Smallwood, 1982).

\section{CONCLUSÕES}

Este estudo mostrou que a freqüência de ocorrência da floração de $D$. odorata foi anual, ao passo que a fenofase frutos imaturos apresentou freqüência anual e frutos maduros supra-anual, com intervalos de até três anos entre episódios de floração e frutos imaturos e até sete anos entre episódios de frutos maduros. Tanto para floração quanto para frutificação o padrão fenológico foi irregular e as correlaçôes com fatores ambientais fracas. Portanto, sugere-se o uso racional dos produtos derivados de Dipteryx odorata, o cumaru, especialmente no que concerne à exploração de seus frutos. Frutos apresentaram um padrão de oferta bastante irregular, especialmente quando maduros, e uma exploração irracional pode afetar a permanência da espécie em determinadas áreas como a EEST, onde o intervalo entre episódios de frutificação pode ser muito longo. Adicionalmente, a diferença de padrões entre áreas sugere cautela na generalização de dados fenológicos de uma espécie para as vastas áreas de florestas onde ocorre e a importância de mais estudos de longa duração em florestas tropicais.

\section{AGRADECIMENTOS}

Os autores agradecem aos revisores anônimos pelas críticas e sugestôes, ao CNPq (Edital Universal 2002 e 2004) pelo apoio financeiro, à Coordenação de Pesquisas em Silvicultura Tropical (CPST) do Instituto Nacional de pesquisas da Amazônia (INPA) pela licença de A.M.P. e à Coordenação de Pesquisas em Clima e Recursos Hídricos (CPCRH) do INPA pelos dados de clima. Pelo Programa de Pós-Graduação em Biologia Vegetal, UNESP - Rio Claro.

\section{BIBLIOGRAFIA CITADA}

Alencar, J.C. 1986. Análise de associação estrutural de uma comunidade de floresta tropical umida onde ocorre Aniba rosaeodora Ducke (Lauraceae). Tese de Doutorado em Ciências Biológicas. Curso de Pós-Graduação. INPA/FUA. 337p.

---- 1988. Estudos silviculturais de uma população natural de Copaifera multijuga Hayne - Leguminosae, na Amazônia Central. IV. Interpretação de dados fenológicos em relação a elementos climáticos. Acta Amazonica, 18(3-4):199-209.

---- 1994. Fenologia de cinco espécies arbóreas tropicais de Sapotaceae correlacionada a variáveis climáticas na Reserva Ducke, Manaus, AM. Acta Amazonica, 24(3/4):161-182.

Alencar, J.C.; Almeida, R.A.; Fernandes, N.P. 1979. Fenologia de espécies florestais em Floresta Tropical Úmida de Terra Firme na Amazônia Central. Acta Amazonica 9(1):163-198.

Almeida, E.M. de; Alves, M.A.S. 2000. Fenologia de Psychotria nuda e P. brasiliensis (Rubiaceae) em uma área de floresta atlântica no sudeste do Brasil. Acta Botanica Brasilica. 14(3):335-346.

Araújo, V. C. 1970. Fenologia de essências florestais Amazônicas I. Boletim do INPA, Manaus, (4):1-25.

Cavalcante, P. B. 1988. Frutas comestiveis da Amazônia. 4 ed. Belém:Museu Paraense Emílio Goeldi; Companhia Souza Cruz Indústria e Comércio. 279pp

Chapman, C.A.; Chapman, L.J.; Struhsakei, T.T.; Zanne, A.E.; Clark, C.J.; Poulsen, J.R. 2005. A long-term evaluation of fruiting phenology: importance of climate change. Journal of Tropical Ecology 21(01):3145 .

Clay, J.W.; Sampaio, P.T.B.; Clement, C.R. 1999. Biodiversidade amazônica: exemplos e estratégias de utilização. SEBRAE/AM. 1. ed. Programa de Desenvolvimento Empresarial e Tecnológico, Manaus. 409pp.

Ducke, A.; Black, G.A. 1954. Nota sobre a fitogeografia da Amazônia brasileira. Bol. Téc. Inst. Agron. do Norte, 29:3-48.

Howe, H.F.; Smallwood, J. 1982. Ecology of seed dispersal. Annual Review of Ecology and Systematics 13:201-228.

Krebs, C.J. 1994. Ecology: the experimental analysis of distribution and abundance. $4^{\text {th }}$ ed.: Harper-Collins College Publishers, New York. 801 pp.

Lima Júnior, M.J.V. 1992. Fenologia de cinco espécies de Lecythidaceae da Reserva Florestal Ducke, Manaus, AM. Dissertação de Mestrado INPA/ FUA, Manaus, 72p.

Loureiro, A.A. Silva, M.F. da; Alencar, J.C. 1979. Essências madeireiras da Amazônia. INPA, Manaus. 187 pp.

Magalhães, L.M.S.; Alencar, J.C. 1979. Fenologia do Pau-rosa (Aniba duckei Kostermans), Lauraceae, em Floresta Primária na Amazônia Central. Acta Amazonica, 9(2):227-232. 
Newstrom, L.E.; Frankie, G.W.; Baker, H.G. 1994a. A new classification for plant phenology based on flowering patterns in lowland Tropical Rain Forest trees at La Selva, Costa Rica. Biotropica, 26(2):141-159.

Newstrom, L.E.; Frankie, G.W.; Baker, H.G.; Colwell, R.K. 1994b. Diversity of long-term flowering patterns. In: Hespenheide, H. A.; Hartshorn, G. S. (Eds) 1994. La Selva: Ecology and Natural History of a Neotropical Rain Forest. The University of Chicago Press, Chicago. p.142-160.

Morellato, L.P.C.; Talora, D.C.; Takahasi, A.; Benche, C.C.; Romera, E.C.; Ziparro, V.B. 2000. Phenology of Atlantic rain forest trees: a comparative study. Biotropica 32 (4b): 811-823.

Morellato, L.P.C. 2003. Phenological data, networks, and research: South America, In Schwartz, M.D. (Ed.) 2003. Phenology: An Integrative Environmental Science. Tasks for Vegetation Sciences Kluwer Academic Publishers, Dordrecht. Netherlands. p.75-92.

Pedroni, F.; Sanchez, M.; Santos, F.A.M. 2002. Fenologia da copaíba (Copaifera langsdorffii Desf. - Legumisosae, Caesalpinioideae) em uma floresta semidecídua no sudeste do Brasil. Revista Brasileira de Botânica, 25(2):183-194.

Pereira, A.P.; Pedroso, L.M. 1982. Dados fenológicos das principais espécies florestais que ocorrem na Estação Experimental de Curuá-Una-Pará. In: Anais do Congresso Nacional Sobre Essências Nativas. São Paulo-Brasil. Edição especial. 16(2):1175-1182.

Pinto, A.M.; Ribeiro, R.J; Alencar, J.C.; Barbosa, A.P. 2005. Fenologia de Simarouba amara Aubl. na Reserva Florestal Adolpho Ducke, Manaus, AM. Acta Amazonica, 35(3):347-352.

Prance, G.T. 1975. The correct name for Castanha de Cutia (Couepia edulis Prance - Chrysobalanaceae). Acta Amazonica, 5(2):143-145.

RADAMBRASIL 1978. Departamento Nacional da Produção Mineral. Projeto RADAMBRASIL. Folha SA.20 Manaus; geologia, geomorfologia, pedologia, vegetação e uso do potencial da terra. Rio de Janeiro. 628p. Ilust., tab., 7 mapas. Levantamento de Recursos Naturais, 18.
Revilla, J. 2000. Plantas da Amazônia: oportunidades econômicas e sustentáveis. SEBRAE/AM. 1. ed. Programa de Desenvolvimento Empresarial e Tecnológico, Manaus. 405p.

Ribeiro, M.N.G. 1976. Aspectos climatológicos de Manaus. Acta Amazonica, 6(2):229-233.

Ruiz, J.E.A.; Alencar, J.C. 1999. Phenological interpretation of five Chrysobalanaceae tree species in the Adolpho Ducke Forest Reserve, Manaus, Amazonas, Brazil. Acta Amazonica 29(2): 223-242.

Ruiz, J.E.A.; Alencar, J.C. 2004. Comportamento fenológico da palmeira patauá (Oenocarpus bataua) na Reserva Florestal Adolpho Ducke, Manaus, Amazonas, Brasil. Acta Amazonica 34(4): 553-558.

Silva, M.F.; Lisboa, P.L.B.; Lisboa, R.C.L. 1977. Nomes vulgares de plantas amazônicas. INPA, Belém-PA. 222pp.

Umaña, C.L.A.; Alencar, J.C. 1993. Comportamento fenológico da SucupiraPreta (Diplotropis purpurea Rich. Amsh. var. coriacea Amsh. ) na Reserva Florestal Ducke. Acta Amazonica, 23(1):199-211.

Veloso, H.P.; Rangel Filho, A.L.R.;Lima, J.C.A. 1991. Classificação da Vegetação Brasileira, adaptada a um sistema universal. IBGE, Departamento de Recursos Naturais e Estudos Ambientais, Rio de Janeiro. 124pp.

Zar, J.H. 1996. Biostatistical Analysis. $3^{\text {th }}$ Edition. Prentice Hall, Upper Sanddle River, New Jersey. 662pp.

Recebido em 27/10/2004

Aceito em 21/10/2008 
